\title{
Digital Social Multitasking (DSMT), Friendship Quality, and Basic Psychological Needs Satisfaction Among Adolescents: Perceptions as Mediators
}

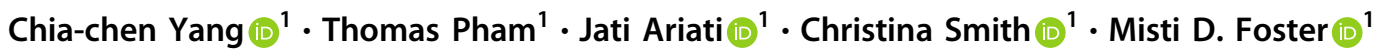

Received: 5 March 2021 / Accepted: 23 April 2021 / Published online: 15 May 2021

(c) The Author(s), under exclusive licence to Springer Science+Business Media, LLC, part of Springer Nature 2021

\begin{abstract}
Most existing research assumes "phone use during face-to-face interactions" to be psychosocially detrimental. Drawing on the digital social multitasking framework, this study explored not only the negative but also positive implications of the behavior. A sample of 517 adolescents $\left(M_{\text {age }}=14.83\right.$, S.D. $=1.93 ; 50 \%$ female $)$ recruited through the Qualtrics panel completed an online survey. Results showed that adolescents' and their friend's digital social multitasking were both associated with (1) greater perceived efficiency, which, in turn, was associated with competence need satisfaction, and (2) greater perceived connection, which, in turn, was associated with better friendship quality, autonomy need satisfaction, and relatedness need satisfaction. Adolescents' own multitasking also had an indirect, negative relationship with friendship quality through perceived distraction, but friend's multitasking did not compromise friendship quality. The study provides a more balanced picture, showing that despite the potential harm of digital social multitasking, adolescents' phone use during face-to-face peer interactions also involves potential benefits for teens' psychosocial well-being.
\end{abstract}

Keywords Phubbing $\cdot$ Technoference $\cdot$ Mobile communication $\cdot$ Friendship quality $\cdot$ Basic psychological needs $\cdot$ Wellbeing

\section{Introduction}

In the United States, access to a smartphone has reached $95 \%$ among adolescents, and $45 \%$ of teens are almost always online (Anderson \& Jiang, 2018). Phone use appears ubiquitous, even when people have face-to-face interactions with others. According to a national survey, $89 \%$ of adult cell phone owners used their phones during their most recent social activity with others (Rainie \& Zickuhr, 2015). Although there has been growing research on the psychosocial implications of this behavior, most studies focus on how this behavior hinders interactions and compromises the quality of a relationship among adults (e.g., McDaniel et al., 2020; Roberts \& David, 2016). There is little discussion of

Chia-chen Yang

chia-chen.yang@okstate.edu

1 School of Educational Foundations, Leadership and Aviation, Oklahoma State University, 217 Willard Hall, Stillwater, OK 74078, USA what positive experiences may derive from the behavior and what developmental needs this behavior may fulfill among adolescents. To present a more comprehensive illustration of this popular activity among youth, this study drew on the digital social multitasking framework (Yang \& Christofferson, 2020) to explore both the negative and positive implications of adolescents' phone use during face-to-face interactions with their friends.

\section{Negative Perceptions of Digital Social Multitasking}

Research on the psychosocial implications of phone use during social interactions has been dominated by the theoretical frameworks of technoference (McDaniel \& Coyne, 2016) and phubbing (Roberts \& David, 2016), in which technology use during an interaction is viewed as an interference (hence the term technoference) and phone use as a snub (hence the term phubbing). However, more recently, scholars noted that a norm shift might be taking place and the behavior is not necessarily perceived negatively (Kelly et al., 2017, 2019; Vanden Abeele et al., 2019). Thus, a neutral framework that does not assume 
technology use during social interactions to be problematic and attends to both positive and negative sides of the behavior is needed to capture the whole picture.

Against this backdrop, the framework of digital social multitasking, defined as "technology-based multitasking during a social interaction" (p. 1210), was developed (Yang \& Christofferson, 2020). Under this framework, one should consider both the conditions in which people themselves are multitasking and the scenarios in which their communication partners are multitasking. In both circumstances, one should pay attention to the level of engagement, perceptions, and the contexts in which the behavior occurs.

The distinction between the level of digital social multitasking and the perceptions of the behavior is particularly noteworthy. Although technology use during social interactions can create the feelings of being ignored and interfere with relationships (McDaniel \& Coyne, 2016; Roberts \& David, 2016), people nowadays seem to have become more accepting of this behavior and the behavior per se does not necessarily dampen relationships. In romantic relationships, young adults see their partner's phone use during an interaction as expected, neutral, and typical (Kelly et al., 2017). In friendships, most individuals view their friend's phone use as a normal practice and do not see it as a facethreatening act (Kelly et al., 2019).

Thus, it is plausible that level of digital social multitasking influences users' psychosocial well-being only through their perceptions of the behavior. Indeed, one study found that whereas the level of digital social multitasking did not directly associate with youth's friendship quality and loneliness, it had an indirect relationship with these variables through perceived distraction (when youth themselves multitasked) and perceived dismissiveness (when their friend multitasked; Yang \& Christofferson, 2020). The paths between negative perceptions and poor well-being were consistent with the rich literature of phubbing and technoference. This is not surprising because phubbing and technoference are actually conceptualized as examples of negative perceptions of digital social multitasking in this framework. When users feel snubbed by their partner's phone use (phubbing) or when they perceive technology as an interference in their relationships (technoference), they report lower communication quality and relationship satisfaction (Chotpitayasunondh \& Douglas, 2018; Wang et al., 2017). Mediators of the association include more conflicts in general (McDaniel et al., 2020), more conflicts over technology use in particular (McDaniel \& Coyne, 2016; Roberts \& David, 2016), lower satisfaction with the leisure time spent together (McDaniel et al., 2020), lower sense of belonging, and more negative affect or less positive affect (Chotpitayasunondh \& Douglas, 2018).
Positive Perceptions of Digital Social Multitasking

The dominance of the phubbing and technoference narratives can generate the impression that digital social multitasking only induces negative perceptions. This impression is inaccurate. After all, if a behavior only induces negative effects, individuals should not be motivated to engage in the activity (see a review in Wang \& Tchernev, 2012). Yet, it is clear that digital social multitasking has become a common activity in the digital age (Rainie \& Zickuhr, 2015; Vanden Abeele et al., 2019). Thus, it is imperative to explore the positive perceptions that may derive from the behavior.

Although the digital social multitasking framework recognized the importance of attending to both negative and positive perceptions of the behavior, the initial work drawing on this model did not specify the positive perceptions. Luckily, research on the motives for and gratifications of media multitasking (i.e., simultaneously using multiple media or performing various media activities) provides a clue. This line of research shows that using media to multitask has the potential to gratify users' needs (e.g., Chang, 2017; Hwang et al., 2014; Kononova \& Chiang, 2015; Su \& Chen, 2020; Wang \& Tchernev, 2012). These needs and gratifications arguably reflect the positive perceptions one may experience in media multitasking.

Four major needs/gratifications emerged across studies: information access, efficiency, entertainment, and connection. Individuals are motivated to multitask with media because they can get the information they need and control the information consumed (Hwang et al., 2014; Kononova \& Chiang, 2015). This motive/gratification reflects users' cognitive needs underlying media multitasking (Chang, 2017; Wang \& Tchernev, 2012). People are also drawn to media multitasking because they perceive it as efficient and time-saving (Chang, 2017; Hwang et al., 2014; Kononova \& Chiang, 2015). In fact, information and efficiency have been found to be the top two motives for media multitasking (Hwang et al., 2014; Kononova \& Chiang, 2015). Entertainment is another major motive for media multitasking; the fun and enjoyable nature of the activity gratifies users' emotional needs (Chang, 2017; Hwang et al., 2014; Kononova \& Chiang, 2015; Su \& Chen, 2020; Wang \& Tchernev, 2012). Finally, as more media are designed for communication and interaction, media multitasking also has the great potential to generate a sense of connection and enhance social experiences (Chang, 2017; Hwang et al., 2014; Kononova \& Chiang, 2015; Su \& Chen, 2020; Wang \& Tchernev, 2012).

Digital social multitasking and media multitasking differ in that in the former, technology-based multitasking has to take place during a social interaction, whereas in the latter, one can engage in multiple media activities without any being social (e.g., watching TV while surfing the Internet; 
Kononova \& Chiang, 2015). Despite the difference, the two share the multitasking nature, making the motives and gratifications derived from the media multitasking research applicable to digital social multitasking. In other words, individuals are often motivated to multitask with media to gain gratifications of information access, efficiency, entertainment, and connection, and it is plausible that adolescents would also develop these four positive perceptions after they perform digital social multitasking. Regarding the scenarios in which adolescents' friends multitask, it is noteworthy that phone-based, multitasked activities are often shared between the communication partners (Kelly et al., 2017, 2019). For example, one's friend may multitask to solve a shared problem and share information with or forward a fun meme to the person (Yang \& Christofferson, 2020). Thus, adolescents may also develop the four positive perceptions when their friends multitask. To conclude, digital social multitasking may generate the four positive perceptions both when adolescents themselves multitask and when their friends multitask in their presence.

\section{Psychosocial Well-Being}

The primary goal of the current study is to examine the psychosocial implications of digital social multitasking through negative as well as positive perceptions of this behavior. The study focused on friendship quality and basic psychological needs satisfaction as the two well-being variables. Their individual roles in adolescent development are discussed in the following sections.

\section{Friendship quality}

Friendship quality is pivotal to adolescent development. It facilitates desirable behaviors and serves as a protective factor against undesirable outcomes. For example, friendship quality predicts adolescents' supportive behaviors in romantic relationships (Schacter et al., 2019). Furthermore, while peer victimization predicts poor socioemotional wellbeing, and peer rejection predicts less support provision in romantic relationships, these associations are mitigated among adolescents reporting high-quality friendships (Cuadros \& Berger, 2016; Schacter et al., 2019). Conversely, poor friendship quality predicts the onset of maladaptive behaviors in friendships, such as keeping secrets (Corsano et al., 2017) and telling lies (Dykstra et al., 2020). Moreover, the quality of friendships during adolescence has long-term implications for adulthood mental health (e.g., depression; Chen et al., 2020). In sum, the significance of adolescents' friendship quality manifests across various developmental contexts.

Quality and satisfaction of relationships, including friendships, is among the most widely studied outcome variables in the research of technology use during social interactions (e.g., McDaniel et al., 2020; Yang \& Christofferson, 2020). It is clear that negative perceptions of digital social multitasking (e.g., technoference and phubbing) are associated with poor relationship quality (Chotpitayasunondh \& Douglas, 2018; McDaniel et al., 2020). On the other hand, positive perceptions of digital social multitasking and their implications for relationship quality remain largely unknown. Despite the lack of direct evidence, there is reason to believe that positive perceptions of the behavior would associate with better friendship quality. For instance, when individuals use their phone in the presence of a communication partner, they share what they see and do on the phone, and they feel positive about this practice (Kelly et al., 2017). In fact, some users start digital social multitasking because they are eager to show something to their communication partner (Yang \& Christofferson, 2020) or because it is a relational routine enjoyed by themselves and their partner (Kelly et al., 2017). By providing materials to share and discuss, digital social multitasking may generate a sense of connection, which then enhances the quality of the relationship. In sum, it was expected that negative perceptions of digital social multitasking would associate with poorer friendship quality, whereas positive perceptions would associate with better friendship quality.

\section{Basic psychological needs satisfaction}

According to the self-determination theory (Ryan \& Deci, 2000), basic psychological needs refer to psychological necessities that specify the conditions for motivation, well-being, and psychological growth. They include the needs for autonomy, competence, and relatedness. Autonomy refers to a sense of volition, self-directedness, and freedom from coercion; competence is characterized by a sense of mastery and effectiveness and can be gained through overcoming intrinsically rewarding challenges; the need for relatedness is the desire to establish a connection with other people, and is satisfied when warmth and reciprocal care are experienced (Ryan \& Deci, 2000; Ryan et al., 2016).

Satisfying the basic psychological needs is crucial for adolescent development. It contributes to the cultivation of intrinsic motivation and self-regulation, which are associated with learning, task performance and persistence, and effective adjustment to and interaction with the social environment (Ryan \& Deci, 2000). In the context of schools, needs satisfaction is associated with better school adjustment (Ratelle \& Duchesne, 2014) and school-related subjective well-being (Tian et al., 2014). In the context of everyday lives, needs satisfaction relates to better psychological and subjective well-being (Rodríguez-Meirinhos et al., 2020; 
Thomaes et al., 2017), partly because it makes adolescents feel comfortable being who they are (Thomaes et al., 2017). In contrast, needs frustration is associated with internalizing problems, externalizing problems, and social and cognitive problems (Rodríguez-Meirinhos et al., 2020). Recently, a study using a sample involving both adolescents and adults explored needs satisfaction in the context of mobile communication and noted that, as in other contexts, needs satisfaction was associated with better psychological well-being (Halfmann \& Rieger, 2019).

Media use has the potential to satisfy the basic psychological needs (Reinecke et al., 2012; Tamborini et al., 2011). In fact, one reason why successful media products (e.g., video games) are engaging is that they gratify users' needs for autonomy, competence, and relatedness (Rigby \& Ryan, 2016). What remains unknown is how digital social multitasking, a media-related behavior, would relate to the satisfaction of these needs. It is conceivable that digital social multitasking would relate to needs satisfaction through negative and positive perceptions of the behavior, with negative perceptions associated with lower satisfaction and positive perceptions associated with greater satisfaction. Indeed, empirical evidence has revealed the deleterious implications of negative perceptions for needs satisfaction. For example, when people feel pressured to engage in mobile communication, they report lower satisfaction with the need for autonomy and competence (Halfmann \& Rieger, 2019). Furthermore, when individuals feel distracted by their phone use and when they feel dismissed by a friend's phone use, they report greater loneliness (Yang \& Christofferson, 2020), which likely indicates lower satisfaction of the need for relatedness. The relationship between technoference/phubbing and interpersonal conflicts (McDaniel \& Coyne, 2016; McDaniel et al., 2020; Roberts \& David, 2016) as well as lower sense of belonging (Chotpitayasunondh \& Douglas, 2018) also suggests that when individuals perceive digital social multitasking as a negative experience, their need for relatedness is less likely to be satisfied.

Conversely, positive perceptions of digital social multitasking should relate to greater satisfaction of the basic psychological needs. Although this hypothesis has not been directly examined, a few studies looking into how media activities gratify users' needs provide indirect clues. For instance, according to one recent publication, reading, writing, and sharing on a social Question and Answering site satisfied the needs for autonomy, competence, or relatedness (Cui \& Ji, 2019). The authors' rationales indicated that the various online activities satisfied basic psychological needs because they gave users easy access to and control over information (perceived information access) and allowed users to connect with others (perceived connection). Furthermore, users read, wrote, and shared based on their interests (Cui \& Ji, 2019), which likely made it a fun experience, and experiencing media use as fun and enjoyable is a defining feature of perceived entertainment (e.g., Chang, 2017; Kononova \& Chiang, 2015). Another study also reported that satisfaction of the autonomy and competence needs was associated with enjoyment of Facebook use (Reinecke et al., 2014). Although in that path model, needs satisfaction was an antecedent of enjoyment, the research design was a onetime survey (Reinecke et al., 2014). Thus, it was equally possible that perceived enjoyment/entertainment contributed to needs satisfaction. Perceived efficiency was not discussed in these studies, but it is plausible that managing multiple tasks within a short timeframe (perceived efficiency) would gratify the need for competence. As mentioned in a previous section, these positive perceptions may emerge and mediate the association between digital social multitasking and needs satisfaction even in the scenario in which one's communication partner multitasks, because the phone-based activities often involve both communication partners (Kelly et al., 2017; Yang \& Christofferson, 2020). To conclude, perceiving a technology behavior to be distracting or dismissive should associate with lower satisfaction of the basic psychological needs for autonomy, competence, and relatedness, whereas perceiving the behavior as granting information access, facilitating efficiency, providing entertainment, and enhancing connection should associate with greater satisfaction of the needs.

\section{Current Study}

Existing literature skews toward exploring the negative effects of phone use during social interactions. This study aimed to present a more balanced picture. Specifically, it investigated how digital social multitasking would associate with adolescents' friendship quality and satisfaction of basic psychological needs through their negative and positive perceptions of the behavior. Negative perceptions of technology use have been found to associate with poorer relationship quality, lower satisfaction of the needs for autonomy and competence, and compromised sense of belonging. In contrast, positive perceptions of technology use have the potential to improve relationship quality and satisfy the basic psychological needs. Informed by existing theories and research, it was hypothesized that adolescents' and friend's levels of digital social multitasking would associate with dampened friendship quality and needs satisfaction through negative perceptions of the behavior, but with greater friendship quality and needs satisfaction through positive perceptions of the behavior. 


\section{Method}

\section{Participants and Procedure}

Adolescents between the ages of 12 and 18 were recruited through the Qualtrics panel in the fall of 2020.

This service allowed clients to distribute surveys to a specific group of respondents. The authors of this study requested that the sample be representative of the national population in terms of the gender and racial/ethnic distribution and have a roughly equal split across ages. Three attention checks were embedded in the online survey. Responses from participants who passed at least two attention checks were considered valid data. The final sample involved 517 participants $\left(M_{\mathrm{age}}=14.83\right.$, S.D. $=$ 1.93; $50 \%$ female; $69 \%$ White or European American; 17\% Latinx, Hispanic, or Mexican American; 13\% Black or African American; 6\% Asian or Asian American). Parental consent and adolescent assent were obtained before the participants accessed the survey. Compensation was provided based on the agreement between each participant and Qualtrics. There was no missing data. The study was approved by the Social-BehavioralEducational IRB.

\section{Measures}

Participants completed scales measuring levels and perceptions of digital social multitasking, friendship quality, and satisfaction of the basic psychological needs. Because COVID-19 likely impacted adolescents' peer interactions and phone use, respondents were asked to answer the questions by considering their general experience (i.e., how they would act or feel in their normal life when there was no COVID-19). The survey went through two stages of piloting. First, the authors distributed it to several adolescents they personally knew and collected feedback from the adolescents. These adolescents were between the ages of 13 and 17 and were from different racial/ethnic backgrounds. Incomprehensible or ambiguous survey items were modified based on the feedback. Afterwards, the survey was piloted with 36 adolescents through the Qualtrics panel service. Cronbach's $\alpha$ s were reviewed and it was concluded that the scales had acceptable internal reliability.

In addition to these scales of interest, participants also reported the amount of phone use in a typical day $(M=$ $5.18, S . D .=2.88)$ through a pull-down menu $(1=0$ to 1 $h, 13=$ More than $12 \mathrm{~h}$ ). The result showed that the average was slightly above 4 to 5 hours. The amount of phone use served as a control variable in the path models.

\section{Level of digital social multitasking}

The measures were adapted from the ones used in a previous study (Yang \& Christofferson, 2020). Participants were instructed to respond to the questions by thinking of one particular friend with whom they had frequent face-toface interactions. The questions were "In general, when you have face-to-face interactions with this friend, how often do YOU do something else on the phone (e.g., texting, browsing, etc.)" and "In general, when you have face-toface interactions with this friend, how often does THIS FRIEND do something else on the phone (e.g., texting, browsing, etc.)" $(1=$ Rarely, $2=$ Sometimes, $3=$ Often, $4=A$ lot $)$. The two scores reflected the participant's level of digital social multitasking $(M=2.77, S . D .=0.96)$ and the friend's level of digital social multitasking $(M=2.73$, S.D. $=0.92)$, respectively. In the Self scale, $10.8 \%$ reported rarely, $28.0 \%$ sometimes, $34.4 \%$ often, and $26.7 \%$ a lot. In the Friend scale, 9.3\% reported rarely, 32.1\% sometimes, $35.2 \%$ often, and $23.4 \%$ a lot.

\section{Negative perceptions of digital social multitasking}

Participants' negative perceptions of their own and the friend's digital social multitasking were measured using the Negative Perception of Digital Social Multitasking scales (Yang \& Christofferson, 2020; $1=$ Strongly disagree, $4=$ Strongly agree). Participants responded to the items by thinking of the above-mentioned friend. The 5-item scale of the negative perception of one's own multitasking ( $\alpha=$ $0.74 ; M=2.58, S . D .=0.67)$ reflected the degree to which participants felt distracted by their phone use (e.g., "I feel distracted by the phone"). The 5-item scale of the negative perception of friend's multitasking $(\alpha=0.80 ; M=2.57$, $S . D .=0.75)$ reflected the extent to which participants felt dismissed by the friend due to the friend's phone use (e.g., "The friend's phone use during the interactions makes me feel ignored").

\section{Positive perceptions of digital social multitasking}

Twelve items from the Motivations to Multitask with Media Scale (Kononova \& Chiang, 2015) were adapted to measure positive perceptions. The 12 items were from the subscales of control, efficiency, entertainment, and connection. (The original scale had the fifth subscale of addiction, but it was excluded from the current study as it did not concern positive perceptions.) The authors of this study selected and modified the items to make them more reflective of a digital social multitasking context. The authors referred to other media multitasking motive scales (e.g., Chang, 2017; Hwang et al., 2014) and digital social multitasking literature 
Table 1 Results of confirmatory factor analysis: positive perceptions of self DSMT

\begin{tabular}{lll}
\hline & Factor loading & $\alpha$ \\
\hline Phone use during the interactions: & & 0.78 \\
Information Access & & \\
Allows me to get the information I need & 0.74 & \\
Allows me to get the information of my & 0.73 & \\
interest & & \\
Makes me feel like I have all the information & 0.74 & \\
at hand & & \\
Efficiency & 0.74 \\
Allows me to complete tasks efficiently & 0.78 & \\
Makes me feel efficient & 0.75 & \\
Allows me to get things done more efficiently & 0.81 \\
Entertainment & & \\
Is enjoyable & 0.79 & \\
Is entertaining & 0.75 & \\
Is fun & 0.76 & \\
Connection & & \\
Allows me to connect with multiple people & 0.63 & \\
Makes me feel closer to people & 0.74 & \\
Enhances my social experiences & 0.76 & \\
\hline
\end{tabular}

The scale instruction read: Think of the times when you do something on the phone while having a face-to-face interaction with the abovementioned friend. How much do you agree with the following? The scale was a 5-point Likert scale

(e.g., Kelly et al., 2017; Yang \& Christofferson, 2020) during this process. Shorter and easier phrases were adopted to make the items comprehensible to adolescents. As mentioned above, the scale items were piloted with adolescents of the targeted ages before the official launch of the study ( $\alpha s=0.71$ to 0.92 from the pilot sample). The final scale measured positive perceptions of information access, efficiency, entertainment, and connection. Participants were asked how much they agreed with the statements when they or the above-mentioned friend did something on the phone while the two had face-to-face interactions $(1=$ Strongly disagree, $\quad 4=$ Strongly agree). Participants responded to the 12 items twice, once by considering their own multitasking and the other by considering the friend's multitasking. See Tables 1, 2 for the items and psychometric properties.

\section{Friendship quality}

Friendship quality was measured using 5 items from the Relationship Assessment Scale (Hendrick 1988). The items were revised to reflect the assessment of friendship quality rather than the quality of romantic relationships. Participants responded to items such as "In general, I'm satisfied
Table 2 Results of confirmatory factor analysis: positive perceptions of friend DSMT

\begin{tabular}{lll}
\hline & Factor loading & $\alpha$ \\
\hline The friend's phone use during the interactions: & & 0.84 \\
Information Access & & \\
Allows us to get the information we need & 0.80 & 0.77 \\
Allows us to get the information of our & & \\
interest & 0.80 & 0.86 \\
Makes me feel like we have all the & & \\
information at hand & & \\
Efficiency & 0.83 & \\
Allows us to complete tasks efficiently & 0.82 & \\
Makes me feel efficient & 0.78 \\
Allows us to get things done more efficiently & \\
Entertainment & 0.90 & \\
Is enjoyable & 0.85 & \\
Is entertaining & 0.77 & \\
Is fun & & \\
Connection & 0.79 \\
Allows us to connect with multiple people & 0.64 & \\
Makes me feel closer to people & 0.80 & \\
Enhances my social experiences & 0.79 & \\
\hline
\end{tabular}

The scale instruction read: Think of the times when the abovementioned friend does something on the phone while having a face-toface interaction with you. How much do you agree with the following? The scale was a 5-point Likert scale

with this friendship" $(1=$ Strongly disagree, $5=$ Strongly agree). A higher mean score reflected better friendship quality ( $\alpha=0.86 ; M=4.36, S . D .=0.65)$.

\section{Basic psychological needs satisfaction}

The satisfaction of basic psychological needs has been studied in various contexts (e.g., schools, everyday lives), with mobile communication being the most relevant context given the focus of the study (i.e., phone use during a social interaction). Therefore, the Intrinsic Need Satisfaction Scale in Mobile Communication (Halfmann \& Rieger, 2019) was adapted to measure how well participants' needs for autonomy, competence, and relatedness were fulfilled during mobile communication. Each subscale included 4 items $(1=$ Does not apply at all, $5=$ Fully applies), starting with the stem "How well does each of the following statements apply to you when you use your phone?" Sample items included "I do not feel pressured to behave in a certain way" (autonomy; $\alpha=0.81$; $M=4.08$, S.D. $=0.76$ ), "I feel competent" (competence; $\alpha=0.83 ; M=4.05$, S.D. $=0.77)$, and "I feel that other people care about me" (relatedness; $\alpha=0.83 ; M=4.15$, S.D. $=0.76)$. 
Fig. 1 Path Analysis Model of Associations Between DSMT and Friendship Quality and Needs Satisfaction. Numbers are standardized coefficients. DSMT Digital Social Multitasking. The thin lines represent significant direct paths. The bold lines represent significant indirect paths. For clarity of presentation, controlled paths are not presented. $* p<0.05$; $* * p<0.01 ; * * * p<0.001$

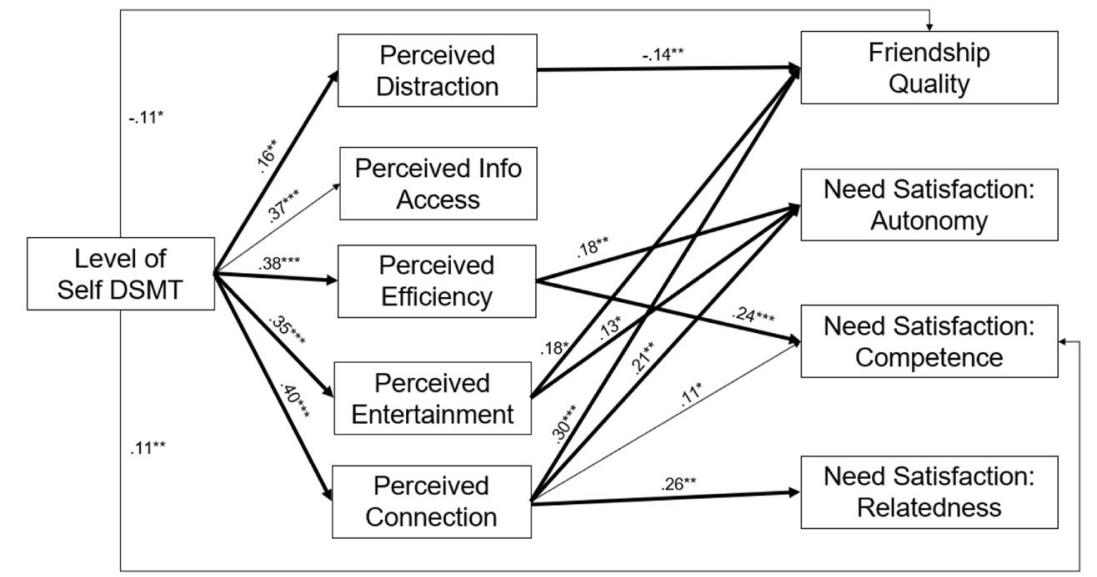

a) Self DSMT Model

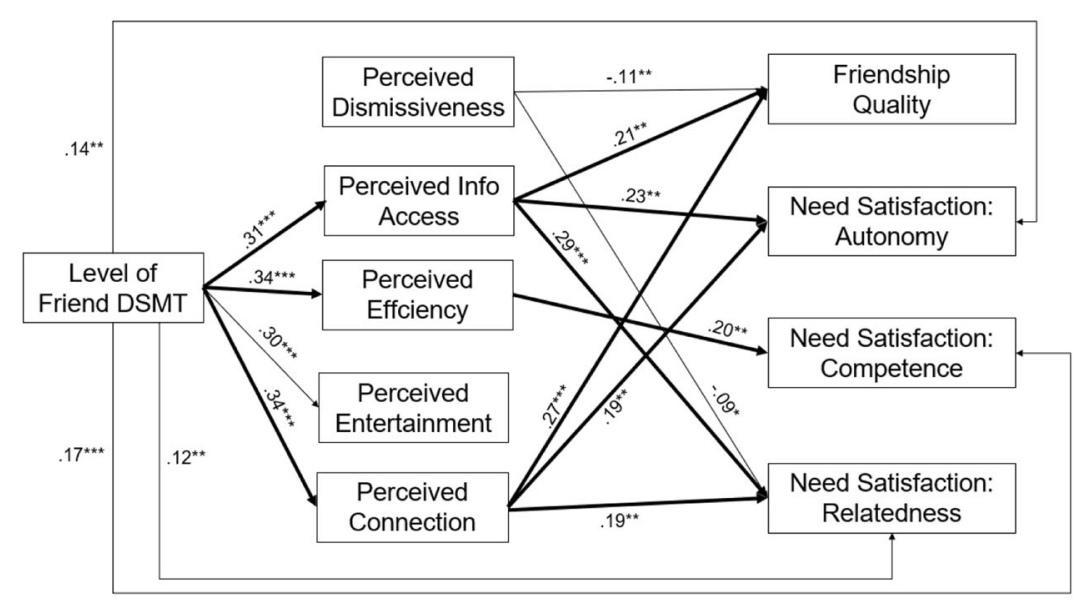

b) Friend DSMT Model

\section{Plan for Analysis}

Confirmatory factor analysis (CFA) of the scales of Positive Perceptions was performed, after which the hypothesized path models were examined. In the self-as-multitasker path model, friendship quality and satisfaction of the three basic psychological needs were regressed on the negative and positive perceptions of one's own multitasking. Perceptions, as mediators, were then regressed on the level of one's own multitasking (see Fig. 1a). The friend-as-multitasker model followed the same path structure but involved variables related to the friend's, rather than the self's, multitasking (see Fig. 1b). In both path models, friendship quality and needs satisfaction were also regressed on the level of digital social multitasking so that the unique contribution of perceptions could be revealed. Control variables included age, gender, and amount of phone use. Furthermore, the mediators were allowed to correlate, and so were the outcome variables.
All analyses were performed using Mplus, with maximum likelihood robust (MLR) being the estimator. Model fit was assessed by considering the following criteria: the comparative fit index (CFI) and the Tucker-Lewis index (TLI) being close to or greater than 0.95 , and the root mean square error of approximation (RMSEA) being smaller than 0.06 (Hu \& Bentler, 1999). For CFA, factor loadings were expected to be close to or greater than 0.70 (Hair et al., 2011).

\section{Results}

\section{Confirmatory Factor Analysis of the Positive Perceptions Scales}

The presumed 4-factor structure of the Positive Perceptions scales was supported. For positive perceptions of one's own 


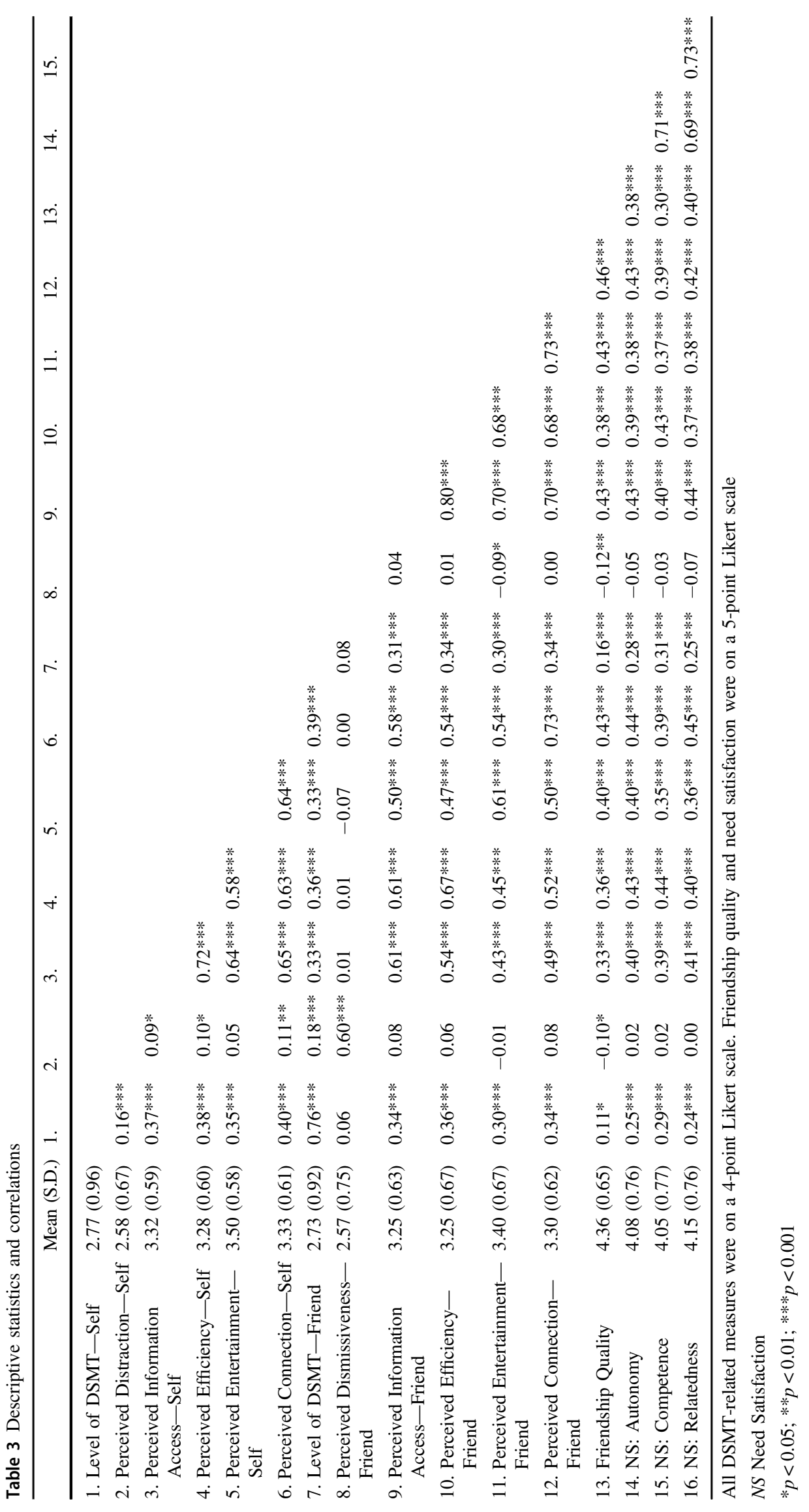


multitasking: $\chi^{2}(48)=85.15, p<0.001$; RMSEA $=0.039$, 90\% CI [0.025-0.052]; $\mathrm{CFI}=0.979$; TLI $=0.971$. All but one factor loading were above 0.70 , ranging from 0.63 to 0.79. For positive perceptions of friend's multitasking: $\chi^{2}(48)=100.08, p<0.001 ;$ RMSEA $=0.046,90 \%$ CI $[0.033-0.058] ; \mathrm{CFI}=0.980 ; \mathrm{TLI}=0.972$. All but one factor loading were greater than 0.70 , ranging from 0.64 to 0.90 . See Tables 1,2 for factor loadings and Cronbach's $\alpha$ s. Also see Table 3 for descriptive statistics and correlations ${ }^{1}$.

\section{Path Analyses of Psychosocial Implications of Digital Social Multitasking (DSMT)}

The path model of Self DSMT (i.e., the self-as-multitasker model) fit well: $\chi^{2}(15)=30.22, p=0.011$; RMSEA $=$ $0.044,90 \%$ CI $[0.021-0.067]$; CFI $=0.992$; TLI $=0.961$. See Table 4 for the path coefficients. The level of one's DSMT was associated with all the mediators, lower friendship quality, and higher competence need satisfaction, but not with the satisfaction of autonomy and relatedness needs. A negative perception of being distracted was associated with lower friendship quality but not any of the needs satisfaction. Positive perception of having easy access to information was not associated with any outcome variables. Perceived efficiency was associated with satisfaction of the needs for autonomy and competence, but not with relatedness and friendship quality. Perceived entertainment was related to higher friendship quality and satisfaction of the need for autonomy but not with competence and relatedness. Perceived connection was positively associated with all outcome variables. Eight indirect paths were

\footnotetext{
${ }^{1}$ As shown in Table 3, a few positive perceptions had high correlations $(>0.70$ ), and thus additional CFAs were performed to examine whether those scales should have been combined. When Perceived Information-Self and Perceived Efficiency-Self were combined, the model fit was fine, but the adjusted $\chi^{2}$ showed a significant change (Sattora-Bentler Scaled Chi-Square Difference $=14.96, \Delta \mathrm{df}=3, p=$ 0.002), suggesting that the four-factor model was a better one. Similarly, when Perceived Information-Friend and Perceived Efficiency-Friend were combined, the model fit was fine, but the adjusted $\chi^{2}$ showed a significant change (Sattora-Bentler Scaled ChiSquare Difference $=8.76, \Delta \mathrm{df}=3, p=0.033$ ), suggesting that the four-factor model was a better one. Because combining the most strongly correlated perceptions already hurt model fit, no further modification (combination) was performed. In the initial analysis, factor analysis was not performed on the need satisfaction scale because it was a published scale. However, because the three satisfactions had high correlations, CFAs were conducted to assess whether the presumed structure was reasonable. The results showed that the three-factor model $\left(\chi^{2}(51)=162.915, p=0.000\right.$; RMSEA $=0.065$, 90\% CI [0.054-0.077]; CFI $=0.945$; TLI $=0.929)$ fit better than the one-factor model $\left(\chi^{2}(54)=243.41, p=0.000\right.$; RMSEA $=0.082,90 \%$ CI [0.072-0.093]; CFI $=0.907$; TLI $=0.886)$ : Sattora-Bentler Scaled Chi-Square Difference $=63.46, \Delta \mathrm{df}=3, p=0.000$. For both statistical and theoretical reasons, the presumed factor structures for positive perceptions and needs satisfaction were retained.
}

Table 4 Path analysis of the self DSMT model

\begin{tabular}{|c|c|c|c|}
\hline & $\beta$ & S.E. & $p$ \\
\hline \multicolumn{4}{|l|}{ Direct Paths of Interest } \\
\hline DSMT level $\rightarrow$ Perceived distraction & 0.16 & 0.05 & 0.001 \\
\hline DSMT level $\rightarrow$ Perceived information access & 0.37 & 0.04 & $<0.001$ \\
\hline DSMT level $\rightarrow$ Perceived efficiency & 0.38 & 0.04 & $<0.001$ \\
\hline DSMT level $\rightarrow$ Perceived entertainment & 0.35 & 0.04 & $<0.001$ \\
\hline DSMT level $\rightarrow$ Perceived connection & 0.40 & 0.04 & $<0.001$ \\
\hline DSMT level $\rightarrow$ Friendship quality & -0.11 & 0.05 & 0.025 \\
\hline DSMT level $\rightarrow$ Autonomy NS & 0.06 & 0.05 & 0.201 \\
\hline DSMT level $\rightarrow$ Competence NS & 0.11 & 0.04 & 0.007 \\
\hline DSMT level $\rightarrow$ Relatedness NS & 0.06 & 0.04 & 0.206 \\
\hline Perceived distraction $\rightarrow$ Friendship quality & -0.14 & 0.04 & 0.001 \\
\hline Perceived distraction $\rightarrow$ Autonomy NS & -0.05 & 0.04 & 0.268 \\
\hline Perceived distraction $\rightarrow$ Competence NS & -0.05 & 0.04 & 0.171 \\
\hline Perceived distraction $\rightarrow$ Relatedness NS & -0.06 & 0.04 & 0.130 \\
\hline Perceived information access $\rightarrow$ Friendship quality & -0.02 & 0.08 & 0.787 \\
\hline Perceived information access $\rightarrow$ Autonomy NS & 0.04 & 0.07 & 0.617 \\
\hline Perceived information access $\rightarrow$ Competence NS & 0.07 & 0.07 & 0.324 \\
\hline Perceived information access $\rightarrow$ Relatedness NS & 0.12 & 0.07 & 0.081 \\
\hline Perceived efficiency $\rightarrow$ Friendship quality & 0.12 & 0.08 & 0.125 \\
\hline Perceived efficiency $\rightarrow$ Autonomy NS & 0.18 & 0.07 & 0.008 \\
\hline Perceived efficiency $\rightarrow$ Competence NS & 0.24 & 0.06 & $<0.001$ \\
\hline Perceived efficiency $\rightarrow$ Relatedness NS & 0.11 & 0.07 & 0.091 \\
\hline Perceived entertainment $\rightarrow$ Friendship quality & 0.18 & 0.07 & 0.014 \\
\hline Perceived entertainment $\rightarrow$ Autonomy NS & 0.13 & 0.06 & 0.025 \\
\hline Perceived entertainment $\rightarrow$ Competence NS & 0.07 & 0.06 & 0.245 \\
\hline Perceived entertainment $\rightarrow$ Relatedness NS & 0.06 & 0.07 & 0.395 \\
\hline Perceived connection $\rightarrow$ Friendship quality & 0.30 & 0.06 & $<0.001$ \\
\hline Perceived connection $\rightarrow$ Autonomy NS & 0.21 & 0.06 & 0.001 \\
\hline Perceived connection $\rightarrow$ Competence NS & 0.11 & 0.06 & 0.048 \\
\hline Perceived connection $\rightarrow$ Relatedness NS & 0.26 & 0.08 & 0.001 \\
\hline \multicolumn{4}{|l|}{ Significant Indirect Paths of Interest } \\
\hline $\begin{array}{l}\text { DSMT level } \rightarrow \text { Perceived distraction } \rightarrow \text { Friendship } \\
\text { quality }\end{array}$ & -0.02 & 0.01 & 0.016 \\
\hline $\begin{array}{l}\text { DSMT level } \rightarrow \text { Perceived efficiency } \rightarrow \\
\text { Autonomy NS }\end{array}$ & 0.07 & 0.03 & 0.010 \\
\hline $\begin{array}{l}\text { DSMT level } \rightarrow \text { Perceived efficiency } \rightarrow \\
\text { Competence NS }\end{array}$ & 0.09 & 0.03 & $<0.001$ \\
\hline $\begin{array}{l}\text { DSMT level } \rightarrow \text { Perceived entertainment } \rightarrow \\
\text { Friendship quality }\end{array}$ & 0.07 & 0.03 & 0.015 \\
\hline $\begin{array}{l}\text { DSMT level } \rightarrow \text { Perceived entertainment } \rightarrow \\
\text { Autonomy NS }\end{array}$ & 0.04 & 0.02 & 0.024 \\
\hline $\begin{array}{l}\text { DSMT level } \rightarrow \text { Perceived connection } \rightarrow \text { Friendship } \\
\text { quality }\end{array}$ & 0.12 & 0.03 & $<0.001$ \\
\hline $\begin{array}{l}\text { DSMT level } \rightarrow \text { Perceived connection } \rightarrow \\
\text { Autonomy NS }\end{array}$ & 0.08 & 0.03 & 0.001 \\
\hline $\begin{array}{l}\text { DSMT level } \rightarrow \text { Perceived connection } \rightarrow \\
\text { Relatedness NS }\end{array}$ & 0.11 & 0.03 & 0.001 \\
\hline \multicolumn{4}{|l|}{ Significant Controlled Paths } \\
\hline Amount of phone use $\rightarrow$ Friendship quality & 0.08 & 0.03 & 0.024 \\
\hline Female $\rightarrow$ Competence NS & -0.15 & 0.08 & 0.046 \\
\hline
\end{tabular}

NS Need Satisfaction

significant-the level of one's own DSMT indirectly associated with lower friendship quality through perceived distraction; however, it also indirectly associated with higher friendship quality and satisfaction of the needs for autonomy, competence, and relatedness via the various positive perceptions of DSMT (see Fig. 1a). 
The path model of Friend DSMT (i.e., the friend-asmultitasker model) fit well: $\chi^{2}(15)=25.04, p=0.049$; RMSEA $=0.036,90 \%$ CI $[0.002-0.060] ; \quad$ CFI $=0.995$; $\mathrm{TLI}=0.977$. See Table 5 for the path coefficients. Level of friend's DSMT was positively associated with all positive perceptions of friend's DSMT and all three needs satisfaction, but not with the negative perception of being dismissed and friendship quality. Negative perception of being dismissed was related to lower friendship quality and relatedness need satisfaction. Perceived information access was related to higher friendship quality and satisfaction of the needs for autonomy and relatedness, but not with competence. Perceived efficiency was only associated with higher satisfaction of the need for competence. Perceived entertainment was not related to any outcome variables. Perceived connection was related to higher friendship quality and satisfaction of the needs for autonomy and relatedness, but not with competence. Seven indirect paths were significant - the level of friend's DSMT indirectly associated with higher friendship quality and satisfaction of the needs for autonomy, competence, and relatedness via the various positive perceptions of DSMT (see Fig. 1b).

For the most part, the hypothesis was supported. Adolescents' own level of DSMT was indeed associated with poorer friendship quality through the negative perception of being distracted. Simultaneously, both adolescents' and their friend's DSMT were associated with greater friendship quality and needs satisfaction through positive perceptions. Two sets of positive indirect paths were consistent across the two models: (1) Level of DSMT was related to perceived efficiency, which contributed to satisfaction of the need for competence, and (2) level of DSMT was related to perceived connection, which contributed to higher friendship quality and satisfaction of the needs for autonomy and relatedness. Unexpectedly, although perceived dismissiveness in the Friend DSMT model was indeed associated with poorer friendship quality and relatedness need satisfaction, the indirect paths from the level to the outcomes were not significant. Furthermore, the direct path from adolescents' own DSMT to poor friendship quality was noteworthy as this path was not expected to be significant given the results from studies using emerging adult or adult samples (e.g., Kelly et al., 2017, 2019; Vanden Abeele et al., 2019). These findings are discussed in the next section.

\section{Discussion}

Technology use during social interactions has become a common activity (Rainie \& Zickuhr, 2015; Vanden Abeele et al., 2019). While much has been studied about how such technology use would compromise users' relationship quality and satisfaction (Chotpitayasunondh \& Douglas,
Table 5 Path analysis of the friend DSMT model

\begin{tabular}{|c|c|c|c|}
\hline & $\beta$ & S.E. & $p$ \\
\hline \multicolumn{4}{|l|}{ Direct Paths of Interest } \\
\hline DSMT level $\rightarrow$ Perceived dismissiveness & 0.08 & 0.05 & 0.073 \\
\hline DSMT level $\rightarrow$ Perceived information access & 0.31 & 0.04 & $<0.001$ \\
\hline DSMT level $\rightarrow$ Perceived efficiency & 0.34 & 0.04 & $<0.001$ \\
\hline DSMT level $\rightarrow$ Perceived entertainment & 0.30 & 0.04 & $<0.001$ \\
\hline DSMT level $\rightarrow$ Perceived connection & 0.34 & 0.04 & $<0.001$ \\
\hline DSMT level $\rightarrow$ Friendship quality & -0.02 & 0.05 & 0.663 \\
\hline DSMT level $\rightarrow$ Autonomy NS & 0.14 & 0.05 & 0.002 \\
\hline DSMT level $\rightarrow$ Competence NS & 0.17 & 0.04 & $<0.001$ \\
\hline DSMT level $\rightarrow$ Relatedness NS & 0.12 & 0.04 & 0.004 \\
\hline Perceived dismissiveness $\rightarrow$ Friendship quality & -0.11 & 0.04 & 0.004 \\
\hline Perceived dismissiveness $\rightarrow$ Autonomy NS & -0.08 & 0.04 & 0.079 \\
\hline Perceived dismissiveness $\rightarrow$ Competence NS & -0.05 & 0.04 & 0.195 \\
\hline Perceived dismissiveness $\rightarrow$ Relatedness NS & -0.09 & 0.04 & 0.023 \\
\hline Perceived information access $\rightarrow$ Friendship quality & 0.21 & 0.07 & 0.002 \\
\hline Perceived information access $\rightarrow$ Autonomy NS & 0.23 & 0.08 & 0.002 \\
\hline Perceived information access $\rightarrow$ Competence NS & 0.10 & 0.08 & 0.230 \\
\hline Perceived information access $\rightarrow$ Relatedness NS & 0.29 & 0.08 & $<0.001$ \\
\hline Perceived efficiency $\rightarrow$ Friendship quality & -0.06 & 0.07 & 0.447 \\
\hline Perceived efficiency $\rightarrow$ Autonomy NS & 0.01 & 0.08 & 0.902 \\
\hline Perceived efficiency $\rightarrow$ Competence NS & 0.20 & 0.07 & 0.005 \\
\hline Perceived efficiency $\rightarrow$ Relatedness NS & -0.05 & 0.07 & 0.520 \\
\hline Perceived entertainment $\rightarrow$ Friendship quality & 0.11 & 0.07 & 0.128 \\
\hline Perceived entertainment $\rightarrow$ Autonomy NS & 0.03 & 0.06 & 0.630 \\
\hline Perceived entertainment $\rightarrow$ Competence NS & 0.04 & 0.07 & 0.590 \\
\hline Perceived entertainment $\rightarrow$ Relatedness NS & 0.04 & 0.07 & 0.608 \\
\hline Perceived connection $\rightarrow$ Friendship quality & 0.27 & 0.06 & $<0.001$ \\
\hline Perceived connection $\rightarrow$ Autonomy NS & 0.19 & 0.06 & 0.001 \\
\hline Perceived connection $\rightarrow$ Competence NS & 0.10 & 0.07 & 0.143 \\
\hline Perceived connection $\rightarrow$ Relatedness NS & 0.19 & 0.07 & 0.005 \\
\hline \multicolumn{4}{|l|}{ Significant Indirect Paths of Interest } \\
\hline $\begin{array}{l}\text { DSMT level } \rightarrow \text { Perceived info access } \rightarrow \text { Friendship } \\
\text { quality }\end{array}$ & 0.07 & 0.02 & 0.005 \\
\hline $\begin{array}{l}\text { DSMT level } \rightarrow \text { Perceived info access } \rightarrow \\
\text { Autonomy NS }\end{array}$ & 0.07 & 0.03 & 0.006 \\
\hline $\begin{array}{l}\text { DSMT level } \rightarrow \text { Perceived info access } \rightarrow \\
\text { Relatedness NS }\end{array}$ & 0.09 & 0.03 & 0.001 \\
\hline $\begin{array}{l}\text { DSMT level } \rightarrow \text { Perceived efficiency } \rightarrow \\
\text { Competence NS }\end{array}$ & 0.07 & 0.03 & 0.009 \\
\hline $\begin{array}{l}\text { DSMT level } \rightarrow \text { Perceived connection } \rightarrow \rightarrow \\
\text { Friendship quality }\end{array}$ & 0.09 & 0.02 & $<0.001$ \\
\hline $\begin{array}{l}\text { DSMT level } \rightarrow \text { Perceived connection } \rightarrow \\
\text { Autonomy NS }\end{array}$ & 0.06 & 0.02 & 0.003 \\
\hline $\begin{array}{l}\text { DSMT level } \rightarrow \text { Perceived connection } \rightarrow \\
\text { Relatedness NS }\end{array}$ & 0.06 & 0.02 & 0.008 \\
\hline \multicolumn{4}{|l|}{ Significant Controlled Paths } \\
\hline Amount of phone use $\rightarrow$ Frie & 0.08 & 0.03 & 0.015 \\
\hline
\end{tabular}

Info Information, NS Need Satisfaction

2018; Wang et al., 2017), little is known about the potential benefits of this practice. The study explored the negative and positive psychosocial implications of digital social multitasking by attending to adolescents' perceptions of the behavior. Overall, adolescents perceived digital social multitasking positively. Although adolescents' own (but not the friend's) multitasking had an indirect relationship with poor friendship quality through a negative perception, both 
adolescents' and the friend's multitasking also contributed to better friendship quality and satisfaction of the basic psychological needs via positive perceptions of the behavior.

\section{Perceptions and Psychosocial Implications of Digital Social Multitasking}

Even though adolescents reported a certain level of perceived distraction (in their own multitasking) and dismissiveness (in their friend's multitasking), their overall perception of this behavior was quite positive, reflected by the high scale scores of perceived information access, efficiency, entertainment, and connection derived from the behavior. It is not surprising that adolescents perceived their own and friend's digital social multitasking to facilitate a sense of connection. Individuals often share what they are currently doing and seeing on the phone with their communication partner, and they perceive this shared activity as an enjoyable and positive experience (Kelly et al., 2017, 2019). Digital social multitasking, which frequently involves social media use and texting/messaging (Yang \& Christofferson, 2020), also allows users to reach people who are not around, through which one can experience connection with a greater network that is not physically present. In other words, digital social multitasking can generate a sense of connection with both the co-present partner and the non-present contacts (also see Kelly et al., 2017). The other three positive perceptions have been discussed less extensively, if at all, in the literature on phubbing and technoference, but they have been identified in the research of media multitasking (e.g., Hwang et al., 2014; Kononova \& Chiang, 2015). The findings of this study confirm that just as when people multitask with media, adolescents appreciate convenient access to information, efficiency, and entertainment, in addition to a sense of connection, in digital social multitasking.

Results of the Self path model showed that, as hypothesized, adolescents' own level of multitasking was associated with lower friendship quality through the perception of being distracted by phone use. The perception of oneself being distracted has been found to associate with poor relationship quality, which can be explained by lower satisfaction with the leisure time spent with the communication partner (McDaniel et al., 2020). It is noteworthy that in this study, adolescents' own level of multitasking also had a direct relationship with poor friendship quality, which was not the case in the studies where participants were mostly emerging adults (Vanden Abeele et al., 2019; Yang \& Christofferson, 2020). The discrepancy may reflect the samples' developmental difference, as reflected by the behavioral and neural evidence. Children and adolescents, relative to adults, are more easily distracted from the primary task by the presence of appealing media distractors (Baumgartner \& Sumter, 2017). They do worse in inhibiting attention to the stimuli that hinder goal achievement (e.g., in an antisaccade task), and engaging the goal-driven attention network appears to be a more effortful process at this developmental stage (Ernst et al., 2011). It suggests the possibility that engagement in multitasking necessarily distracts adolescents from the current interaction and then compromises friendship quality, above and beyond adolescents' perception of the distraction. In contrast, for emerging adults, who likely have better inhibitory control and goal-directed attention (Baumgartner \& Sumter, 2017; Ernst et al., 2011), pure engagement in multitasking is less predictive of psychosocial well-being (Vanden Abeele et al., 2019); it is their perception of being distracted that matters (Yang \& Christofferson, 2020).

The paths from friend's level of multitasking to friendship quality and relatedness need satisfaction via perceived dismissiveness are intriguing. On the one hand, perceived dismissiveness was indeed associated with poorer friendship quality and lower satisfaction of the need for relatedness, which is consistent with the literature of technoference and phubbing (Chotpitayasunondh \& Douglas, 2018; McDaniel et al., 2020). On the other hand, friend's level of multitasking did not associate with perceived dismissiveness, and thus the overall indirect paths were not significant. For the younger generation, many have accepted ubiquitous phone use as a norm (Kelly et al., 2017, 2019). Scholars have noted a possible shift in youth's perceptions of conversational politeness and attentiveness, suggesting that phone use during an interaction is not always perceived negatively (Vanden Abeele et al., 2019). The null association between friend's multitasking and perceived dismissiveness from the current study provides further evidence to this observation.

The psychosocial implications of digital social multitasking appear much more promising when positive perceptions are taken into account. Two sets of indirect paths were consistent between the Self and Friend models. First, adolescents' and friend's levels of multitasking were both associated with perceived efficiency, which, in turn, was associated with satisfaction of the need for competence. The need for competence is fulfilled when people experience effectiveness, feeling they have the efficacy to master a task or skill and to conquer a challenge (Ryan \& Deci, 2000; Ryan et al., 2016). A few studies have shown that media use has the potential to gratify this need, but they focus on entertainment media. For example, after playing a video game requiring much effort and featuring a high level of mental, physical, and temporal demands, users reported greater competence need satisfaction (Reinecke et al., 2012). In a flight simulation game, when users had full control instead of relying on autopilot, they also 
experienced higher satisfaction of the need for competence (Tamborini et al., 2011). The current study also recognizes the role of technologies in the gratification of users' needs, but it expands the research by showing that the gratification can come from how people use a device, in addition to the design or content per se. As mobile phones become an integral part of many people's daily lives, individuals often face competing demands such as being accessible anytime and anywhere while being attentive to the co-present communication partner (Miller-Ott \& Kelly, 2016). Although youth struggle with these competing demands (Miller-Ott \& Kelly, 2016), the challenge brings a silver lining-giving in to the social pressure and fulfilling the social expectations through the use of communication technologies gives people a sense of competence (Reinecke et al., 2014). Adolescents' own multitasking may have satisfied the need for competence by making them feel that they successfully addressed multiple communicative demands within a short period of time (i.e., perceived efficiency). The same result was also identified in the case where adolescents' friend multitasked. Youth often involve the co-present communication partner in their multitasking (Kelly et al., 2017), and they sometimes multitask in order to solve a shared problem or help each other accomplish a task (e.g., properly responding to a text message; see examples in Yang \& Christofferson, 2020). The collaborative nature of youth's digital social multitasking may explain why adolescents experienced a friend's multitasking as efficient and competence-satisfying.

Second, adolescents' and the friend's digital social multitasking levels were both associated with higher perceived connection, which contributed to greater friendship quality and satisfaction of the needs for autonomy and relatedness. Although perceived connection entails feeling connected with an unspecified group of people whereas friendship quality focuses on a particular friend, given that both are relational constructs, it should not be surprising that the two had a significant association. In the digital age, it takes social competence to successfully navigate the socio-technical world and benefit from the utility of technologies (Yang \& Brown, 2015). Digital social multitasking can be challenging. It involves the competing demands of being committed to the co-present partner while being accessible to the non-present associates (Miller-Ott \& Kelly, 2016). It also takes a sophisticated understanding of the implicit ethical codes in peer interaction, such as proper management of screenshots (e.g., when and how to create, share, and keep screenshots); failure to understand and follow the codes can hurt one's peer status and reputation (Jaynes, 2020). Adolescents who felt connected in this context may be the ones who were highly socially competent, and the high-quality friendship was reflecting their social competence (Flannery \& Smith, 2017).
The indirect paths from adolescents' and the friend's levels of multitasking to perceived connection and, finally, to the satisfaction of the needs for autonomy and relatedness resonate with the contemporary conceptualization of the two needs. Although autonomy was once confounded with detachment and seemed to compete with the need for relatedness, more recent research suggests that autonomy and relatedness, in fact, reinforce each other, and both are nurtured through supportive relationships (McElhaney et al., 2009; Ryan et al., 2016). During adolescence, individuals not only negotiate autonomy and relatedness with parents (McElhaney et al., 2009; Manago et al., 2020) but also undergo a similar process with peers when they strive to connect with peers and remain autonomous in the face of peer influence (Allen \& Loeb, 2015). Communication technologies appear to play a facilitating role in helping adolescents achieve both: Texting or computer-mediated communication with friends and parents predict greater closeness with the two parties; furthermore, computermediated communication with parents and friends predicts higher volitional dependence on parents and independent decision making, respectively (Manago et al., 2020). Texting and computer-mediated communication (phone calls, messaging, video-chatting, as operationalized by Manago et al., 2020) are possible practices when youth multitask on the phone. These activities can foster satisfaction of the needs for autonomy and relatedness by creating a sense of connection with the co-present partner and the physically distant networks. While Manago et al. (2020) tested the technology-closeness and technology-autonomy relationships in separate regression models, this study provides further support to the three sets of constructs' interrelatedness by linking them in the same path models.

\section{Implications and Limitations}

This study makes an important theoretical contribution by revealing the positive implications of digital social multitasking. Adolescents' and friend's levels of multitasking indirectly contributed to the satisfaction of all three basic psychological needs (autonomy, competence, and relatedness), with perceived efficiency and connection being the most consistent mediators. Regarding friendship quality, although adolescents' multitasking did associate with perceived distraction and thus lower friendship quality, their own and friend's multitasking also contributed to better friendship quality through perceived connection. The upsides of digital social multitasking have been largely overlooked in existing literature when most attention was paid to technoference and phubbing. The skewed emphasis on the adverse effects of the behavior not only inhibits presentation of the comprehensive picture, but also makes it difficult to explain the popularity of the activity-in the 
current sample, $89.1 \%$ of the participants performed digital social multitasking sometimes or more, and $90.7 \%$ said their friend displayed the behavior sometimes, often, or a lot. Other scholars noted a similar predicament in their research of media multitasking, and argued that, in order to understand why people increasingly multitask, one should look beyond the cognitive impairment multitasking can cause and consider both the gains and losses coming along with the activity (Wang \& Tchernev, 2012; Xu et al., 2019). Resonating with this sentiment, the current study demonstrates the importance of considering both the positive and negative implications of a technology behavior. The fact that engagement in digital social multitasking contributes to positive perceptions of the behavior and thus greater friendship quality and needs satisfaction provides a clue regarding what motivates adolescents to continue the behavior. Recently, studies have shown that technology use during an in-person interaction among emerging adults and adults appears less problematic than once noted (Kelly et al., 2017, 2019; Vanden Abeele et al., 2019). Findings from this study move one step further, unraveling the potential benefits of the behavior, among a younger age group.

At the practical level, the findings may help alleviate the moral panic associated with young people's use of communication technologies (see a similar discussion in Kelly et al., 2019). Although adolescents' own multitasking did associate with lower friendship quality because the multitaskers felt distracted, their own and friend's multitasking largely contributed to positive perceptions of the behavior, which, in turn, were associated with better friendship quality and satisfaction of the needs for autonomy, competence, and relatedness. As discussed by other developmentalists (e.g., Manago et al., 2020; Nesi et al., 2018), communication technologies serve important developmental functions during adolescence. If adults would like adolescents to reduce the behavior when adolescents engage in multitasking with very high frequency, which is more likely to generate negative reactions (Kelly et al., 2019), the results of the study should help the adults understand why this behavior is so engaging for adolescents. From there, adults may discuss with adolescents alternative media or non-media activities that may produce similar positive perceptions and fulfill the identified needs in a mutually acceptable manner.

Despite the contributions, the study have several limitations. First, although the gender and racial/ethnic distributions of the sample were nationally representative, socioeconomic and geographic data were unavailable. Thus, the readers are advised to be cautious in the attempt to generalize the findings. Second, the data were collected at a single time point. Therefore, the directionality between the variables cannot be ascertained. To address this concern, the authors tested alternative models in which perceptions contributed to the level of multitasking, which then influenced well-being outcomes. The models were informed by the research showing that perceptions (gratifications) could shape users' motivation for engaging in the activity (e.g., $\mathrm{Xu}$ et al., 2019). The alternative models showed a poor fit. For the Self model: $\chi^{2}(3)=20.23, p<0.001$; RMSEA $=$ $0.105,90 \%$ CI $[0.065-0.151]$; CFI $=0.983$; TLI $=0.711$. For the Friend model: $\chi^{2}(3)=25.06, p<0.001$; RMSEA $=$ $0.119,90 \%$ CI [0.079-0.164]; CFI $=0.978$; TLI $=0.630$. The results suggest that the presumed directionality is reasonable. However, longitudinal data are still needed to provide stronger evidence. Third, participants were asked to consider their general experience in the normal life when there was no COVID-19. Because the data were collected a few months into the pandemic, it may have been challenging for some participants to accurately recall their prepandemic behaviors and perceptions. The recall bias could lead to attenuated negative perceptions of digital social multitasking (e.g., forgetting how distracting or dismissive it could be). It would be interesting to investigate how the results may differ after the pandemic is over. Fourth, the measures for the level of digital social multitasking involved only one item. The single-item measures had the strengths of straightforwardly assessing the frequency of phone use during face-to-face interactions without overwhelming adolescents with too many questions. However, a full-fledged scale including multiple items would allow one to assess the reliability of the measure more closely. Furthermore, in the current measure, "never" was not a response option. Although the likelihood for an adolescent to "never" engage in digital social multitasking may be low, this possibility cannot be fully ruled out. Thus, future scholars may consider adding this response item to the measure. The respondents who select "never" may not be eligible to answer the perception questions. Fifth, the path models were interpreted by drawing on existing literature documenting the common activities during digital social multitasking (e.g., social media, texting/messaging), but this information was not directly available from the sample. As a few scholars have noted, the context of multitasking often shapes users' perceptions of the behavior. Specifically, individuals are more likely to see a partner's digital social multitasking as face-threatening if the phone-based activity is self-indulgent rather than communicative, and less so if the phone is used to communicate with a boss (Kelly et al., 2019). Furthermore, a negative perception of a friend's digital social multitasking is especially detrimental to friendship quality during a serious (rather than casual) interaction (Yang \& Christofferson, 2020). In the future, scholars may consider asking participants to describe a typical scenario of their multitasking to further the understanding of the behavior and to facilitate data interpretation. 
Finally, media use, including digital social multitasking, is just one source for the satisfaction of basic psychological needs. To unravel the unique contribution of digital social multitasking above and beyond adolescents' general level of adjustment, it would be ideal to control for one's general level of needs satisfaction.

\section{Conclusion}

Phone use during social interactions has become an integral part of young people's social lives. Whereas earlier work in this area focused on the negative impacts of this behavior, this study attended to both the negative and positive implications of this activity. The findings showed that adolescents' and their friend's digital social multitasking were both associated with (1) greater perceived efficiency, which was then associated with competence need satisfaction, and (2) greater perceived connection, which was then associated with better friendship quality, autonomy need satisfaction, and relatedness need satisfaction. Adolescents' own multitasking also had an indirect, negative relationship with friendship quality through perceived distraction, but friend's multitasking did not compromise friendship quality. In short, although digital social multitasking dampened youth's psychosocial well-being as the negative perception was induced, the behavior also played a positive role in adolescent development. It is hoped that these findings will temper readers' concern over adolescents' phone use and recognize or even capitalize on the potential benefits of this behavior. To guide adolescents to use their devices adaptively, it is important to have a balanced view of both the risks and opportunities brought by the devices.

Authors' Contributions C.-c.Y. conceptualized the study, conceived of the design, collected the data, performed the statistical analyses, interpreted the results, and composed the manuscript; T.P. and J.A. assisted with data collection and manuscript composition; C.S. and M.D.F. participated in manuscript composition. All authors read and approved the final manuscript.

Funding The study was supported by a fund provided by the first author's affiliated institution.

Data Sharing and Declaration The dataset generated and/or analyzed during the current study are not publicly available but are available from the corresponding author on reasonable request.

\section{Compliance with Ethical Standards}

Conflict of Interest The author declares no competing interests.

Ethical Approval All procedures performed in studies involving human participants were in accordance with the ethical standards of the institutional and/or national research committee and with the 1964 Helsinki declaration and its later amendments or comparable ethical standards.
Informed Consent Parental consent and adolescent assent were obtained from all individual participants included in the study.

Publisher's note Springer Nature remains neutral with regard to jurisdictional claims in published maps and institutional affiliations.

\section{References}

Allen, J. P., \& Loeb, E. L. (2015). The autonomy-connection challenge in adolescent-peer relationships. Child Development Perspectives, 9(2), 101-105. https://doi.org/10.1111/cdep.12111.

Anderson, M., \& Jiang, J. (2018). Teens, social media \& technology 2018. Pew Research Center. https://www.pewresearch.org/ internet/2018/05/31/teens-social-media-technology-2018/

Baumgartner, S. E., \& Sumter, S. R. (2017). Dealing with media distractions: an observational study of computer-based multitasking among children and adults in the Netherlands. Journal of Children and Media, 11(3), 295-313. https://doi.org/10.1080/ 17482798.2017.1304971.

Chang, Y. (2017). Why do young people multitask with multiple media? Explicating the relationships among sensation seeking, needs, and media multitasking behavior. Media Psychology, 20(4), 685-703. https://doi.org/10.1080/15213269.2016.1247717.

Chen, H., Xiong, P., Chen, L., \& Hao, G. (2020). Childhood neighborhood quality, friendship, and risk of depressive symptoms in adults: the China health and retirement longitudinal study. Journal of Affective Disorders, 276, 732-737. https://doi.org/10. 1016/j.jad.2020.07.090.

Chotpitayasunondh, V., \& Douglas, K. M. (2018). The effects of "phubbing" on social interaction. Journal of Applied Social Psychology, 48(6), 304-316. https://doi.org/10.1111/jasp.12506.

Corsano, P., Musetti, A., Caricati, L., \& Magnani, B. (2017). Keeping secrets from friends: exploring the effects of friendship quality, loneliness and self-esteem on secrecy. Journal of Adolescence, 58, 24-32. https://doi.org/10.1016/j.adolescence. 2017.04.010.

Cuadros, O., \& Berger, C. (2016). The protective role of friendship quality on the wellbeing of adolescents victimized by peers. Journal of youth and adolescence, 45(9), 1877-1888. https://doi. org/10.1007/s10964-016-0504-4.

Cui, D., \& Ji, Q. (2019). What makes social Q\&A site use enjoyable? The role of using modes and intrinsic needs satisfaction. Psychology of Popular Media Culture, 8(3), 190-197. https://doi. org/10.1037/ppm0000177.

Dykstra, V. W., Willoughby, T., \& Evans, A. D. (2020). Lying to friends: examining lie-telling, friendship quality, and depressive symptoms over time during late childhood and adolescence. Journal of Adolescence, 84, 123-135. https://doi.org/10.1016/j. adolescence.2020.08.003.

Ernst, M., Daniele, T., \& Frantz, K. (2011). New perspectives on adolescent motivated behavior: Attention and conditioning. Developmental Cognitive Neuroscience, 1(4), 377-389. https:// doi.org/10.1016/j.den.2011.07.013.

Flannery, K. M., \& Smith, R. L. (2017). Are peer status, friendship quality, and friendship stability equivalent markers of social competence? Adolescent Research Review, 2(4), 331-340. https:// doi.org/10.1007/s40894-016-0042-z.

Hair, J. F., Ringle, C. M., \& Sarstedt, M. (2011). PLS-SEM: indeed a silver bullet. Journal of Marketing Theory and Practice, 19(2), 139-152. https://doi.org/10.2753/MTP1069-6679190202.

Halfmann, A. \& Rieger, D. (2019). Permanently on call: The effects of social pressure on smartphone users' self control, need satisfaction, and well-being. Journal of Computer-Mediated Communication, 24(4), 165-181. https://doi.org/10.1093/jcmc/zmz008. 
Hendrick, S. S. (1988). A generic measure of relationship satisfaction. Journal of Marriage and the Family, 50(1), 93-98. https://doi. org/10.2307/352430.

Hwang, Y., Kim, H., \& Jeong, S. H. (2014). Why do media users multitask?: Motives for general, medium-specific, and contentspecific types of multitasking. Computers in Human Behavior, 36, 542-548. https://doi.org/10.1016/j.chb.2014.04.040.

Hu, L.-t, \& Bentler, P. M. (1999). Cutoff criteria for fit indexes in covariance structure analysis: conventional criteria versus new alternatives. Structural Equation Modeling, 6(1), 1-55. https:// doi.org/10.1080/10705519909540118.

Jaynes, V. (2020). The social life of screenshots: the power of visibility in teen friendship groups. New Media \& Society, 22(8), 1378-1393. https://doi.org/10.1177/1461444819878806.

Kelly, L., Miller-Ott, A. E., \& Duran, R. L. (2017). Sports scores and intimate moments: an expectancy violations theory approach to partner cell phone behaviors in adult romantic relationships. Western Journal of Communication, 81(5), 619-640. https://doi. org/10.1080/10570314.2017.1299206.

Kelly, L., Miller-Ott, A. E., \& Duran, R. L. (2019). Phubbing friends: understanding face threats from, and responses to, friends' cell phone usage through the lens of politeness theory. Communication Quarterly, 67(5), 540-559. https://doi.org/10.1080/01463373. 2019.1668443.

Kononova, A. G., \& Chiang, Y. (2015). Why do we multitask with media? Predictors of media multitasking among internet users in the United States and Taiwan. Computers in Human Behavior, 50, 31-41. https://doi.org/10.1016/j.chb.2015.03.052.

Manago, A. M., Brown, G., Lawley, K. A., \& Anderson, G. (2020). Adolescents' daily face-to-face and computer-mediated communication: Associations with autonomy and closeness to parents and friends. Developmental Psychology, 56(1), 153-164. https:// doi.org/10.1037/dev0000851.

McDaniel, B. T., \& Coyne, S. M. (2016). "Technoference": the interference of technology in couple relationships and implications for women's personal and relational well-being. Psychology of Popular Media Culture, 5(1), 85-98. https://doi.org/10. 1037/ppm0000065.

McDaniel, B. T., Galovan, A. M., \& Drouin, M. (2020). Daily technoference, technology use during couple leisure time, and relationship quality. Media Psychology, Advance Online Publication. https://doi.org/10.1080/15213269.2020.1783561

McElhaney, B. K., Allen, J. P., Stephenson, J. C., \& Hare, A. L. (2009). Attachment and autonomy during adolescence. In R. M. Lerner \& L. Steinberg (Eds.), Handbook of adolescent psychology (pp. 358-403). John Wiley \& Sons, Inc. https://doi.org/10. 1002/9780470479193.adlpsy001012

Miller-Ott, A. E., \& Kelly, L. (2016). Competing discourses and meaning making in talk about romantic partners' cell-phone contact with non-present others. Communication Studies, 67(1), 58-76. https://doi.org/10.1080/10510974.2015.1088876.

Nesi, J., Choukas-Bradley, S., \& Prinstein, M. J. (2018). Transformation of adolescent peer relations in the social media context: part 1-A theoretical framework and application to dyadic peer relationships. Clinical Child and Family Psychology Review, 21 (3), 267-294. https://doi.org/10.1007/s10567-018-0261-x.

Rainie, L., \& Zickuhr, K. (2015). American's view on Mobile Etiquette. Pew Research Center. https://www.pewresearch.org/ internet/2015/08/26/americans-views-on-mobile-etiquette/

Ratelle, C., \& Duchesne, S. (2014). Trajectories of psychological need satisfaction from early to late adolescence as a predictor of adjustment in school. Contemporary Educational Psychology, 39 (4), 388-400. https://doi.org/10.1016/j.cedpsych.2014.09.003.

Reinecke, L., Tamborini, R., Grizzard, M., Lewis, R., Eden, A., \& David Bowman, N. (2012). Characterizing mood management as need satisfaction: The effects of intrinsic needs on selective exposure and mood repair. Journal of Communication, 62(3), 437-453. https://doi.org/10.1111/j.1460-2466.2012.01649.x.

Reinecke, L., Vorderer, P., \& Knop, K. (2014). Entertainment 2.0? The role of intrinsic and extrinsic need satisfaction for the enjoyment of Facebook use: ENTERTAINMENT 2.0? Journal of Communication, 64(3), 417-438. https://doi.org/10.1111/jcom. 12099.

Rigby, C. S., \& Ryan, R. M. (2016). Time well-spent? Motivation for entertainment media and its eudaimonic aspects through the lens of self-determination theory. In L. Reinecke \& M. B. Oliver (Eds.), The Routledge handbook of media use and well-being: International perspectives on theory and research on positive media effects (p. 34-48). Routledge Handbooks Online. https:// doi.org/10.4324/9781315714752.ch3

Roberts, J. A., \& David, M. E. (2016). My life has become a major distraction from my cell phone: Partner phubbing and relationship satisfaction among romantic partners. Computers in Human Behavior, 54, 134-141. https://doi.org/10.1016/j.chb. 2015.07.058.

Rodríguez-Meirinhos, A., Vansteenkiste, M., Soenens, B., Oliva, A., Brenning, K., \& Antolín-Suárez, L. (2020). When is parental monitoring effective? A person-centered analysis of the role of autonomy-supportive and psychologically controlling parenting in referred and non-referred adolescents. Journal of Youth and Adolescence, 49, 352-368. https://doi.org/10.1007/s10964-019-01151-7.

Ryan, R. M., \& Deci, E. L. (2000). Self-determination theory and the facilitation of intrinsic motivation, social development, and wellbeing. American Psychologist, 55(1), 68-78. https://doi.org/10. 1037/0003-066X.55.1.68.

Ryan, R. M., Deci, E. L., \& Vansteenkiste, M. (2016). Autonomy and autonomy disturbances in self-Development and psychopathology: Research on motivation, attachment, and clinical Process. In D. Cicchetti (Ed.), Developmental Psychopathology (pp. 1-54). John Wiley \& Sons, Inc. https://doi.org/10.1002/9781119125556. devpsy 109

Schacter, H., Lessard, L., \& Juvonen, J. (2019). Peer rejection as a precursor of romantic dysfunction in adolescence: can friendships protect? Journal of Adolescence, 77, 70-80. https://doi.org/10. 1016/j.adolescence.2019.10.004.

Su, L., \& Chen, S. (2020). Exploring the typology and impacts of audience gratifications gained from $\mathrm{TV}$-smartphone multitasking. International Journal of Human-Computer Interaction, 36(8), 725-735. https://doi.org/10.1080/10447318.2019.1683312.

Tamborini, R., Grizzard, M., David Bowman, N., Reinecke, L., Lewis, R. J., \& Eden, A. (2011). Media enjoyment as need satisfaction: the contribution of hedonic and nonhedonic needs. Journal of Communication, 61(6), 1025-1042. https://doi.org/10.1111/j. 1460-2466.2011.01593.x.

Thomaes, S., Sedikides, C., van den Bos, N., Hutteman, R., \& Reijntjes, A. (2017). Happy to be "Me?": Authenticity, psychological need satisfaction, and subjective well-being in adolescence. Child Development, 88(4), 1045-1056. https://doi.org/10. 1111/cdev.12867.

Tian, L., Chen, H., \& Huebner, E. S. (2014). The longitudinal relationships between basic psychological needs satisfaction at school and school-related subjective well-being in adolescents. Social Indicators Research, 119(1), 353-372. https://doi.org/10. 1007/s11205-013-0495-4.

Vanden Abeele, M. M. P., Hendrickson, A. T., Pollmann, M. M. H., \& Ling, R. (2019). Phubbing behavior in conversations and its relation to perceived conversation intimacy and distraction: an exploratory observation study. Computers in Human Behavior, 100, 35-47. https://doi.org/10.1016/j.chb.2019.06.004.

Wang, X., Xie, X., Wang, Y., Wang, P., \& Lei, L. (2017). Partner phubbing and depression among married Chinese adults: the roles of relationship satisfaction and relationship length. Personality 
and Individual Differences, 110, 12-17. https://doi.org/10.1016/j. paid.2017.01.014.

Wang, Z., \& Tchernev, J. M. (2012). The "myth" of media multitasking: reciprocal dynamics of media multitasking, personal needs, and gratifications. Journal of Communication, 62(3), 493-513. https://doi.org/10.1111/j.1460-2466.2012.01641.x.

Xu, S., Wang, Z., \& Woods, K. (2019). Multitasking and dual motivational systems: a dynamic longitudinal study. Human Communication Research, 45(4), 371-394. https://doi.org/10. 1093/hcr/hqz009.

Yang, C.-c, \& Brown, B. B. (2015). Factors involved in associations between Facebook use and college adjustment: Social competence, perceived usefulness, and use patterns. Computers in Human Behavior, 46, 245-253. https://doi.org/10.1016/j.chb.2015.01.015.

Yang, C.-c, \& Christofferson, K. (2020). On the phone when we're hanging out: Digital social multitasking (DSMT) and its socioemotional implications. Journal of Youth and Adolescence, 49, 1209-1224. https://doi.org/10.1007/s10964-020-01230-0.

Chia-chen Yang is an Assistant Professor in the School of Educational Foundations, Leadership and Aviation at Oklahoma State University. She received her doctorate in Educational Psychology from the University of Wisconsin-Madison. Her research interests focus on adolescents' and emerging adults' use of communication technologies in relation to young people's social development, sense of self, and psychological well-being.

Thomas Pham is a Ph.D. student studying Educational Psychology at Oklahoma State University. He specializes in Research, Evaluation, Measurement, and Statistics. His research interest is in educational nonprofit program development and evaluation, volunteer motivation and behavior in nonprofit organizations, and racial-ethnic youth and college student social-emotional development.

Jati Ariati is a Ph.D. student studying Educational Psychology at Oklahoma State University. Her research interests focus on social relationships and technology in the classrooms (face-to-face and online) and how those factors contribute to students' sense of belonging, emotion, and learning across cultural groups.

Christina Smith is a Ph.D. student studying Educational Psychology at Oklahoma State University. She also works as an institutional assessment research analyst and adjunct professor for the psychology department at the University of Central Oklahoma. Her research interests primarily include bullying with a special interest in female relational aggression and the impacts that these behaviors have on education and development.

Misti D. Foster is a Ph.D. student in the School of Educational Foundations, Leadership and Aviation at Oklahoma State University. She is also an instructional designer and faculty member in the Center for Learning \& Innovation at Southern Nazarene University. Her research interests lie primarily in the area of teacher-student relationships or perceptions of those relationships, especially in the online learning environment. 